\title{
Creativity through Oracy: A mixed methods study of creativity in L2 talk Abie Chan, Ph.D. Candidate
}

3 @abiechanhuiki Yhkc35@cam.ac.uk

"Creativity is as important as literacy" Sir Ken Robinson

\section{Project Summary}

Promotion of creativity as a Higher-Order Thinking Skill (HOTS) for the $21^{\text {st }}$ century generation has been widely found in the official discourse of the governments worldwide. While numerous attempts have been made to theorise this field, creativity is yet to be found as a buzzword to teachers in translating it to real-life classrooms. The proposed study hopes to contribute to this field by conceptualising creativity as a dialogic process. This project will employ a sociocultural approach to understand how creativity develops through the use L2 talk amongst students under a group setting.

\section{Research Objectives}

1. To understand the relationship between talk and creativity as a higher-order thinking skill

2. To identify a pragmatic solution for ESL (English as a second language) teachers to nurture creativity in the real-life classrooms

\section{Methodology}

Research Design

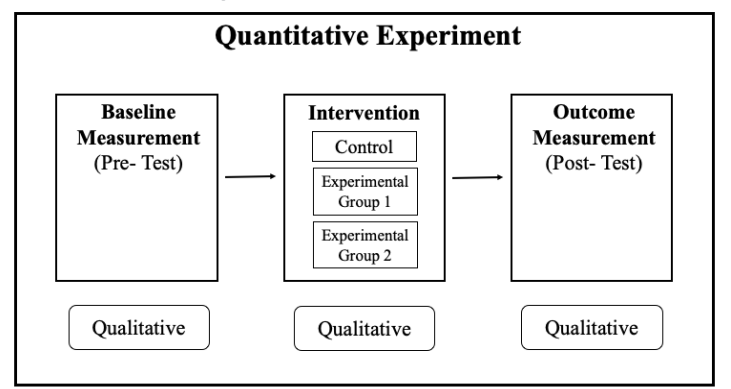

A Mixed Methods Experimental Design (Creswell \& Plano Clark, 2018)

There were three stages within the quantitative experiment:

Before Intervention: $\quad$ Develop the tools and materials used for the intervention through literature review, two Pilot Studies, and Teacher's Training Workshops

During Intervention: $\quad$ Understand how participants experience the treatment conditions through Classroom Observations

After Intervention: $\quad \circ \quad$ Receive participants' feedback on the intervention and explain the outcomes of the intervention through Semi-Structured and StimulatedRecall Interviews

Intervention Programme - Details

A locally aided secondary school in Hong Kong participated in the main study of this project, which involved three Grade 8 classes and their English Language Teachers. Each class was composed of 28 to 33 students. The three classes were randomly allocated into the following three pedagogical conditions for 3.5 months:

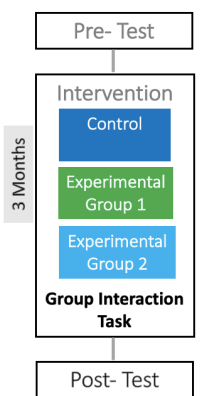

\begin{tabular}{lll}
\hline & & \multicolumn{1}{c}{ Control } \\
\hline Conditions & \multicolumn{1}{c}{ No Talk } \\
\hline Details & $\circ$ & Whole Class Teaching \\
& $\circ$ & NO Group Speaking \\
& Practice in class
\end{tabular}

\section{Creativity Through Oracy:}

Adapted from a well-established framework on children's oracy skills called Thinking Together (Lyn., Mercer, \& Wegerif, 2000) Commit to the mediation and development of creative thinking skills through the effective use of spoken language

Developed based on a wide range of research literature from Psychology, Group Ideation and Brainstorming, Group Work, insights from the two Pilot Studies, and teachers' workshops

\section{Insight from Pilot Studies}

\section{Descriptive Statistics}

The Creativity Through Oracy pedagogy was effective in boosting participants' dialogic performance of creativity, as indicated by improvements in their verbal behaviour and ideational outcomes.

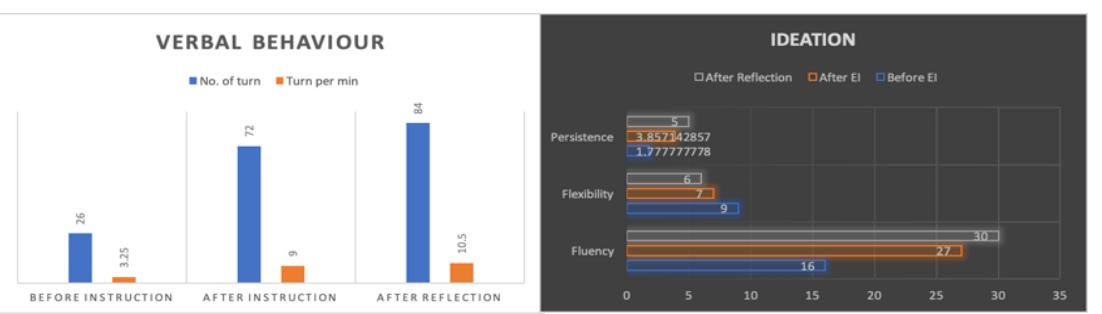

\section{Qualitative Analysis}

The quality of the group interactions between the participants also enhanced, as demonstrated by the occurrence of "creative instances", more personal and affective sharing, and the strategies used to brainstorm ideas.

\section{References}

Creswell, J. W. \& Plano Clark, V. L. (2018). Designing and conducting mixed methods research (3rd ed). London: SAGE Publications, Inc.

Lyn., D., Mercer, N., \& Wegerif, R. (2000). Thinking together: A programme of activities for developing thinking skills at KS2 / by Lyn Dawes, Neil Mercer and Rupert Wegerif. Birmingham: The Questions Publishing.

\section{Preliminary Analysis of Main Study Data}

Participants were found to take spoken language competence for granted

There were misconceptions about creativity as an inborn skill

Metacognition and thinking prompts are important to the activation and development of creative thinking skill

A friendly and non-threatening environment is essential to participants' engagement in group discussions in an ESL (English as a Second Language) classroom

Duration and consistency of the intervention sessions had a profound impact on L2 learners' uptake of the English speaking and creative thinking skills 